\title{
Two Comparable Earthquakes Produced Greatly Different Coseismic Landslides: The 2015 Gorkha, Nepal and 2008 Wenchuan, China Events
}

\author{
Chong $\mathrm{Xu}^{* 1}$, Xiwei $\mathrm{Xu}^{* 1}$, Yingying Tian ${ }^{1}$, Lingling Shen ${ }^{2}, \mathrm{Qi} \mathrm{Yao}^{3}$, Xueqiang Huang ${ }^{4}$, \\ Junxue Ma ${ }^{4}$, Xi Chen ${ }^{4}$, Siyuan Ma \\ 1. Key Laboratory of Active Tectonics and Volcano, Institute of Geology, China Earthquake Administration, Beijing 100029, China \\ 2. Beijing Meteorological Information Center, Beijing Meteorological Service, Beijing 100089, China \\ 3. China Earthquake Networks Center, Beijing 100045, China \\ 4. School of Engineering and Technology, China University of Geosciences, Beijing 100083, China
}

\begin{abstract}
The 2015 Gorkha Earthquake in Nepal and the 2008 Wenchuan Earthquake in China occurred at the south and southeast margins of the Tibetan Plateau, respectively. Both earthquakes had similar magnitudes of $M \mathrm{w} 7.8$ and 7.9, caused catastrophic loss of life and damage to property, and generated tens of thousands of landslides. Comparisons of pre- and post-quake satellite images supported by field investigations show that the Gorkha Earthquake triggered at least 2064 large landslides (defined as covering an area $\geq 10000 \mathrm{~m}^{2}$ ) over a $\sim 35600 \mathrm{~km}^{2}$ region with a volume of $(444-584) \times 10^{6}$ (average $\left.509 \times 10^{6}\right) \mathrm{m}^{3}$ and total area of $44.78 \times 10^{6} \mathrm{~m}^{2}$. In contrast, the Wenchuan Earthquake triggered 25580 large landslides over a region of $\sim 44000 \mathrm{~km}^{2}$ with a volume of $\left(\begin{array}{lll}7 & 128-9 & 479\end{array}\right) \times 10^{6}$ (average $\left.8219 \times 10^{6}\right) \mathrm{m}^{3}$ and a total area of about $670.65 \times 10^{6} \mathrm{~m}^{2}$. Several controlling factors including topographic relief, slope steepness, and regional peak ground acceleration (PGA) were investigated to try to explain the great differences between the number, volume and area of the coseismic landslides associated with the two similar earthquakes. We found that the differences primarily arose from an unexpected factor, the dip angle of the seismogenic fault. This discovery should aid understanding the failure mechanisms of quake-triggered landslides, and suggests that more factors should be taken into consideration in estimating coseismic landslide volumes from earthquake magnitudes.
\end{abstract}

KEY WORDS: Gorkha Earthquake, Wenchuan Earthquake, landslide, dip angle, seismogenic fault.

\section{INTRODUCTION}

The April 25, 2015 Gorkha, Nepal Mw 7.8 and May 12, 2008 Wenchuan, China $M \mathrm{w} 7.9$ earthquakes have received much attention because both were humanitarian disasters that generated large numbers of coseismic landslides and serious damage (Yin and Liu, 2016). The 200000 landslides triggered by the Wenchuan Earthquake significantly changed the landscape of the proximal area; their inventory (Xu et al., 2014a) is the largest ever recorded for landslides caused by an individual earthquake. Relevant papers on the Wenchuan-event landslides describe their database and spatial distribution patterns ( $\mathrm{Xu}$ et al., 2014a; Gorum et al., 2011), discuss the characteristics and mechanisms of large individual landslides (Yin et al., 2015, 2009), provide assessments of landslide susceptibility and hazards (Xu C et al., 2013), and describe the evolution of the

\footnotetext{
*Corresponding author: xuchong@ies.ac.cn; xiweixu@vip.sina.com
}

(C) The Authors 2016. This article is published with open access at Springerlink.com

Manuscript received May 10, 2016.

Manuscript accepted September 30, 2016. geomorphic evolution of the affected area (Xu et al., 2014b; Parker et al., 2011).

Although the Gorkha Earthquake occurred more recently, several studies (Kargel et al., 2016; British Geological Survey and Durham University, 2015; Chiaro et al., 2015; Collins and Jibson, 2015; Hashash et al., 2015; Moss et al., 2015) have described its coseismic landslides using field reconnaissance and satellite images, provided descriptions and analyses of several large individual landslides, and analyzed their controlling factors. Two recently released inventories of coseismic landslides (Kargel et al., 2016; British Geological Survey and Durham University, 2015) record comparable numbers of landslides triggered by the Gorkha Earthquake but neither is a polygon-based inventory, so omissions of coseismic landslides are possible. One of the most interesting results recorded about the Gorkha Earthquake is the unanticipated low number and small scales of coseismic landslides. Kargel et al. (2016) attributed this to a lack of surface ruptures, the 10 to $15 \mathrm{~km}$ depth of concentrated deformation, and the regional lithology but these factors do not seem adequate to explain the actual situation. Therefore we undertook a comparative analysis of landslides associated with the Wenchuan and Gorkha earthquakes to search for other relevant factors.

Xu, C., Xu, X. W., Tian, Y. Y., et al., 2016. Two Comparable Earthquakes Produced Greatly Different Coseismic Landslides: The 2015 Gorkha, Nepal and 2008 Wenchuan, China Events. Journal of Earth Science, 27(6): 1008-1015. doi:10.1007/s12583-016-0684-6. http://en.earth-science.net 
We compiled a polygon-based inventory of large landslides triggered by the Gorkha event, and compared the result to the Wenchuan inventory. We have analyzed and compared correlations between the large coseismic landslides (area $\geq 10000 \mathrm{~m}^{2}$ ) for the two earthquakes with several other relevant factors, such as topographic relief, slope steepness, and PGA. The results show that the Gorkha earthquake-triggered landslides were much fewer in the number, collectively covered a much smaller area, and had a much smaller total volume than those associated with the Wenchuan earthquake-triggered landslides. Our comparisons show that slope angle and PGA were not the primary reasons for the abnormally low occurrence of the Gorkha earthquake-triggered landslides. Instead, we suggest that the disparate dip angles of the seismogenic faults and the resultant differences in the internal rock deformation were the primary reason for the difference. Understanding this factor should improve understanding of coseismic landslide generation mechanisms and help mitigate their associated hazards.

\section{DATA AND METHODS}

\subsection{Geologic Settings}

The 2015 earthquakes of Gorkha, Nepal and 2008 earth- quake of Wenchuan, China occurred respectively at the southern and southeastern boundaries of the Tibetan Plateau (Fig. 1a) The collision between the Indian and Asian continents has created the Himalaya thrust belt (Najman et al., 2010). The present architecture of the belt is dominated by three approximately parallel master thrusts with low dip angles $\left(\sim 10^{\circ}\right)$ : the main frontal thrust (MFT), the main boundary thrust (MBT), and the main central thrust (MCT) (Fig. 1b), listed from south to north in order of increasing age of thrust initiation. The three thrusts divide this region into four tectonic zones: the autochthonous Indian Plate, the Sub-Himalayan zone (SHZ), the Lesser Himalayan sequence (LHS), and the Greater Himalayan sequence (GHS) (Mukherjee, 2015; Bhakuni et al., 2013; Searle et al., 2008; Upreti, 1999; Wesnousky et al., 1999; Le Fort, 1975). All the thrusts are believed to converge at depth into the Main Himalayan thrust (MHT). Results from various methods including field reconnaissance along the main faults and interferometric synthetic aperture radar (InSAR) imaging of the earthquake-affected area, confirm that the Gorkha Earthquake $\left(28.23^{\circ} \mathrm{N}, 84.731^{\circ} \mathrm{E}\right)$ did not produce surface ruptures along faults (Angster et al., 2015; Galetzka et al., 2015; Kobayashi et al., 2015; Lindsey et al., 2015; Parameswaran et al., 2015).

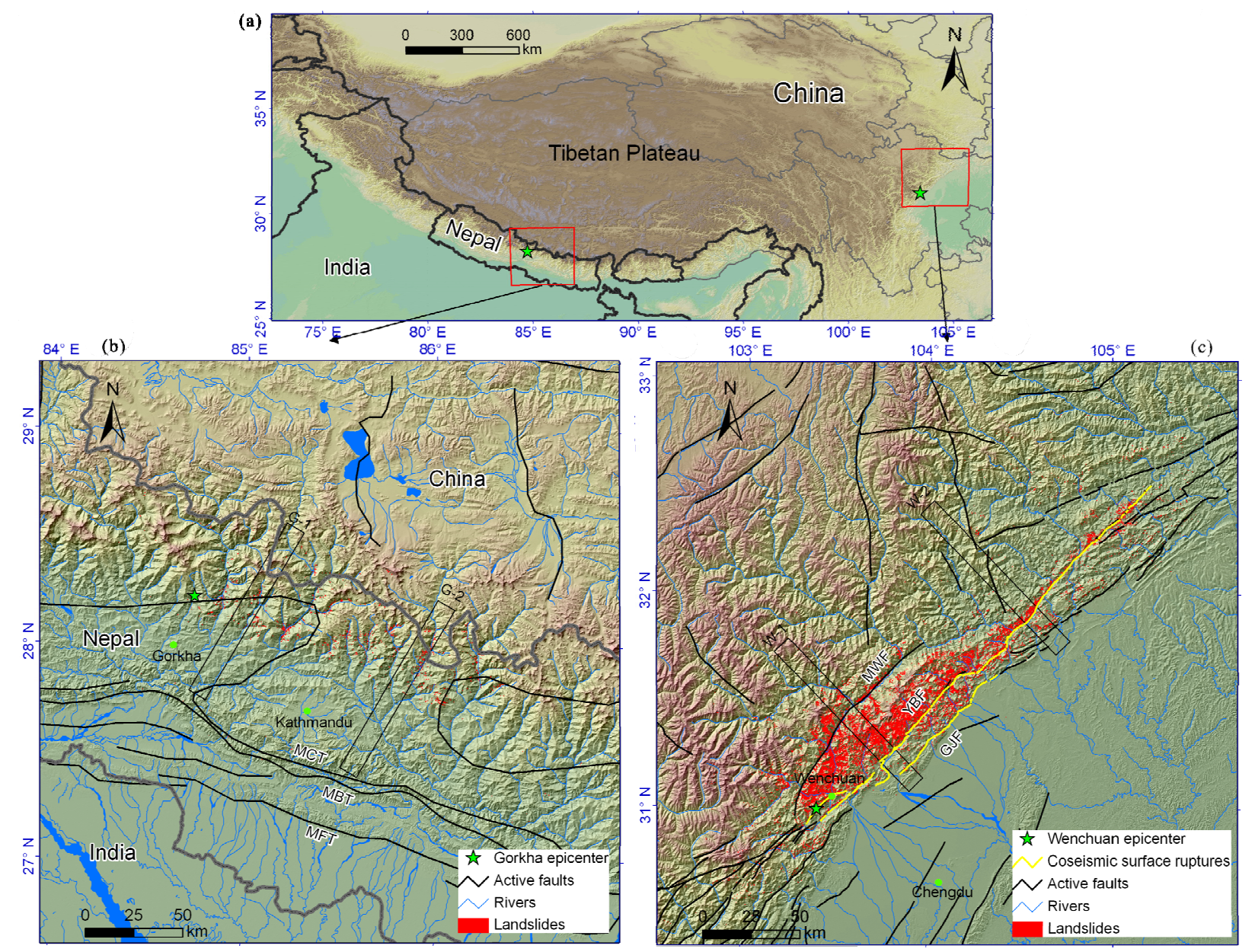

Figure 1. Locations of earthquake epicenters (a) and geologic settings of the Gorkha (b) and Wenchuan (c) earthquakes. Red polygons in (b) and (c) represent large coseismic landslides with individual areas $\geq 10000 \mathrm{~m}^{2}$. MCT. main central thrust; MBT. main boundary thrust; MFT. main frontal thrust; MWF. Maowen fault; YBF. Yingxiu-Beichuan fault; GJF. Guanxian-Jiangyou fault. The four black rectangles N-1, N-2, W-1, and W-2 were target areas for analysis of local topographic relief and slope steepness. 
The Wenchuan Earthquake occurred in the Longmenshan belt that has resulted from extrusion of crustal material from the high Tibetan Plateau in the west against strong crustal material of the Sichuan Basin in the east. The Longmenshan belt is dominated by three main high-dip angle $\left(\sim 40^{\circ}\right)$ fault systems, from northwest to southeast; the Maowen fault (MWF), the Yingxiu-Beichuan fault (YBF), and the Guanxian-Jiangyou fault (GJF) (Fig. 1c). The Wenchuan Earthquake generated two coseismic surface ruptures along the YBF and GJF with lengths of 240 and $72 \mathrm{~km}$, respectively (Xu et al., 2009).

\subsection{Preparing Coseismic Landslide Inventories}

Visual interpretation of satellite images or aerial photographs is the most useful popular method for compiling a coseismic landslide inventory, especially for large earthquakes in mountainous areas $(\mathrm{Xu}, 2015)$. Landslides triggered by such earthquakes often occur in remote areas blocking roads and impeding the timely arrival of ground rescue crews. In addition, the large numbers and wide distribution of landslides triggered by large earthquakes make detailed, comprehensive field investigations impossible. Even so, field renaissance is a very useful auxiliary for visual interpretation of remote sensing images and improving the quality of inventories of landslides. Notable point- or polygon-based inventories of earthquake-triggered landslides include those for the January 17, 1994 Northridge Earthquake, USA (Harp and Jibson, 1995), September 21, 1999 Chi-Chi, Taiwan China Earthquake (Wang et al., 2003), May 12, 2008 Wenchuan Earthquake, China (Xu et al., 2014a; Gorum et al., 2011), and the April 20, 2013 Lushan, China Earthquakes (Xu et al., 2015; Zhang et al., 2015). A landslide is represented by a point in point-based inventories and is delineated as a polygon in polygon-based inventories. Point-based inventories can only describe locations of landslides, whereas polygon-based inventories can depict scales of landslides including landslide area and derived volume. High-resolution images are needed to produce high-quality inventory maps, and are essential for the recognition of small landslides. The accuracy of landslide boundary delineation and the ability to distinguish individual landslides in areas of high landslide density are improved as image quality improves. The pre- and post-quake satellite images used to map the Gorkha landslides were mainly taken from the Google Earth platform and Digital Globe Company, which mostly have resolutions of 0.5 to $2 \mathrm{~m}$. For comparison, the images used to map the landslides triggered by the Wenchuan Earthquake mostly have somewhat lower resolutions of 2.5 to 5 $\mathrm{m}$ (Xu et al., 2014a). In order to avoid inventory map errors arising from the resolution difference for the two areas, we only include landslides with areas exceeding $10000 \mathrm{~m}^{2}$, which are large enough to be clearly seen on either set of images.

\section{RESULTS AND ANALYSIS}

\subsection{Coseismic Landslides Created by the Two Earthquakes}

We have constructed an inventory of large landslides triggered by the Gorkha Earthquake on the basis of visual interpretation of pre- and post-quake satellite images. Several days of field reconnaissance in vehicles and on foot along expedition routes (see Fig. 2a) increase the credibility of our inventory. Our results show that this earthquake triggered at least 2064 landslides exceeding an area of $10000 \mathrm{~m}^{2}$. These landslides cover a total area of $44.78 \times 10^{6} \mathrm{~m}^{2}$. We selected the formula $V=1.3147 \times A^{\left.1.2085^{( \pm 0.013} 1\right)}$ of $\mathrm{Xu}$ et al. (2016) to estimate the total volume from a selection of "volume-area" power law relationships for landslides, (e.g., Xu et al., 2016; Parker et al., 2011; Larsen et al., 2010) because this scaling relation was derived from an original data- based nonlinear least square analysis and sampled 1415 landslides triggered by the Wenchuan Earthquake and is probably the most suitable for landslides triggered by the two earthquakes. The relationship was applied to each slide mass, yielding a total estimated volume of $(444-584) \times 10^{6}$ (average $\left.509 \times 10^{6}\right) \mathrm{m}^{3}$.
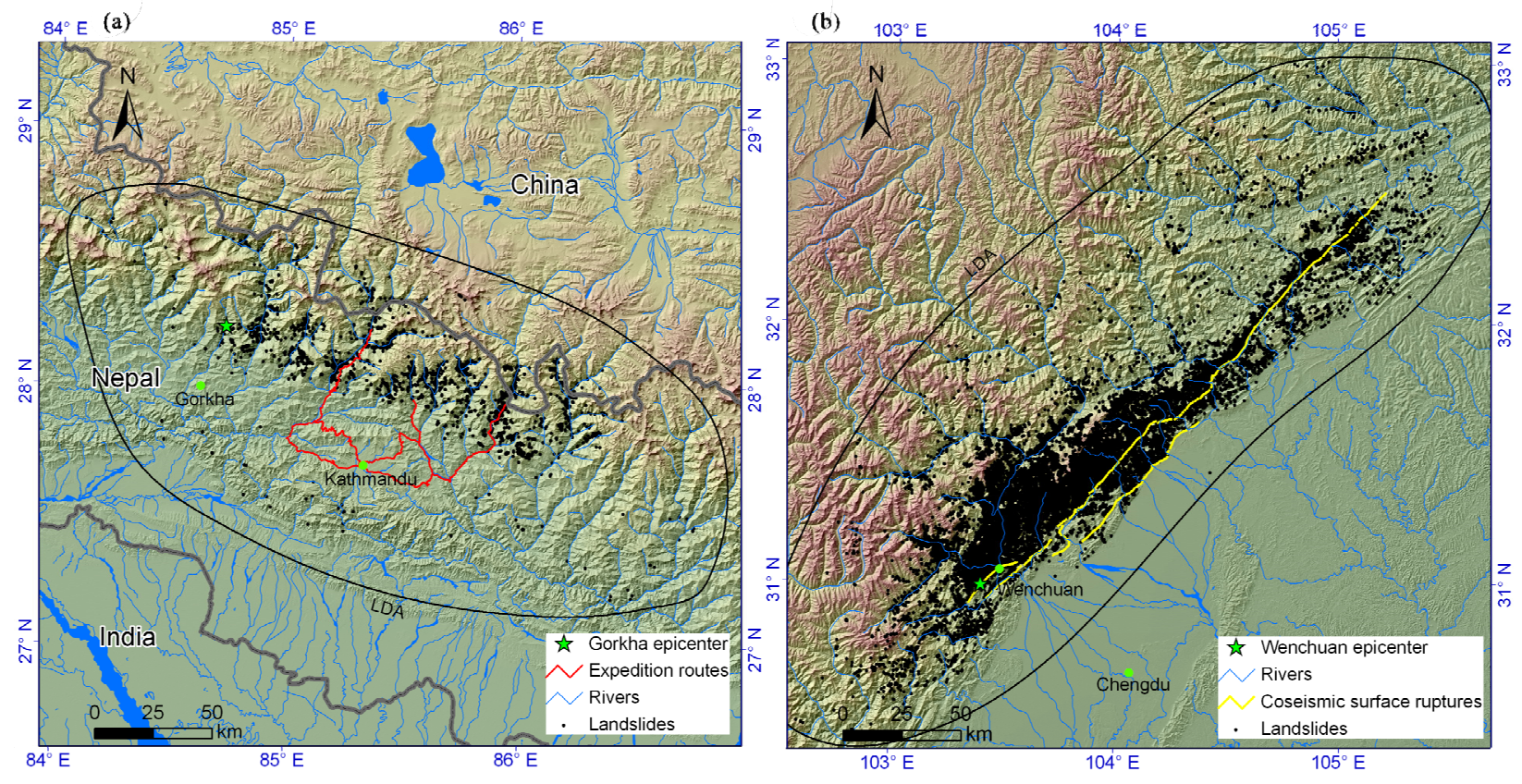

Figure 2. Distribution maps of landslides triggered by the Gorkha, Nepal (a) and Wenchuan, China (b) earthquakes. 
In contrast, 25580 large landslides $\left(\geq 10000 \mathrm{~m}^{2}\right)$ were triggered by the 2008 Wenchuan Earthquake, according to the detailed inventory by Xu et al., 2014a. These landslides collectively cover $670.65 \times 10^{6} \mathrm{~m}^{2}$ and have a total volume $(7128-$ $9479) \times 10^{6}$ (average $8219 \times 10^{6}$ ) $\mathrm{m}^{3}$. There is a startling contrast between large landslides caused by the Gorkha Earthquake which are only $8.1 \%$ in number, $6.7 \%$ in area, and $6.2 \%$ in volume of those generated by the Wenchuan Earthquake. Nevertheless, the sizes of regions of the regions where there was landsliding in these two earthquakes were similar, about 35664 and $44031 \mathrm{~km}^{2}$, respectively.

The relation between landslide area and accumulated number is usefully depicted on a logarithmic graph. Fig. 3 shows two nearly parallel curves that indicate similar power law relationships for the landslides of the two earthquakes, except for a few enormous landslides. This similarity spanning all scales suggests that our inventories of large landslides are quite complete and objective.

Keefer (1994) obtained an empirical power law relationship between earthquake magnitude $(M)$ and total volume $(V)$ of seismic landslides, $\lg V=1.45 M-2.50$, by regression. Using this relationship, the volumes of the $M \mathrm{w} 7.8$ Gorkha and $M \mathrm{w}$ 7.9 Wenchuan earthquakes would be about $646 \times 10^{6} \mathrm{~m}^{3}$ and $902 \times 10^{6} \mathrm{~m}^{3}$, respectively. For comparison, the total volume of the landslides triggered by the Wenchuan Earthquake would be about $11774 \times 10^{6} \mathrm{~m}^{3}$ (a value 13.05 times that suggested by Keefer's equations) using the inventory of 196007 landslides triggered by the Wenchuan Earthquake (Xu et al., 2014a) and the "volume-area" power law relationship $V=1.3147 \times A^{1.2085}$ of $\mathrm{Xu}$ et al. (2016). Unfortunately, currently no inventory is available that spans all scales of coseismic landslides triggered by the Gorkha Earthquake. Therefore, we estimated the total volume of Gorkha-event landslides by simple scaling of the Wenchuan-event results, using the respective volumes of large $\left(\geq 10000 \mathrm{~m}^{2}\right)$ landslides, supported by the nearly parallel trends in Fig. 3. This indicated that the volume of all landslides triggered by the Gorkha Earthquake can be estimated as $\left(11774 \times 10^{6} \mathrm{~m}^{3}\right) \times\left(509 \times 10^{6} \mathrm{~m}^{3} / 8219 \times 10^{6} \mathrm{~m}^{3}\right)$, i.e., $729 \times 10^{6} \mathrm{~m}^{3}$,

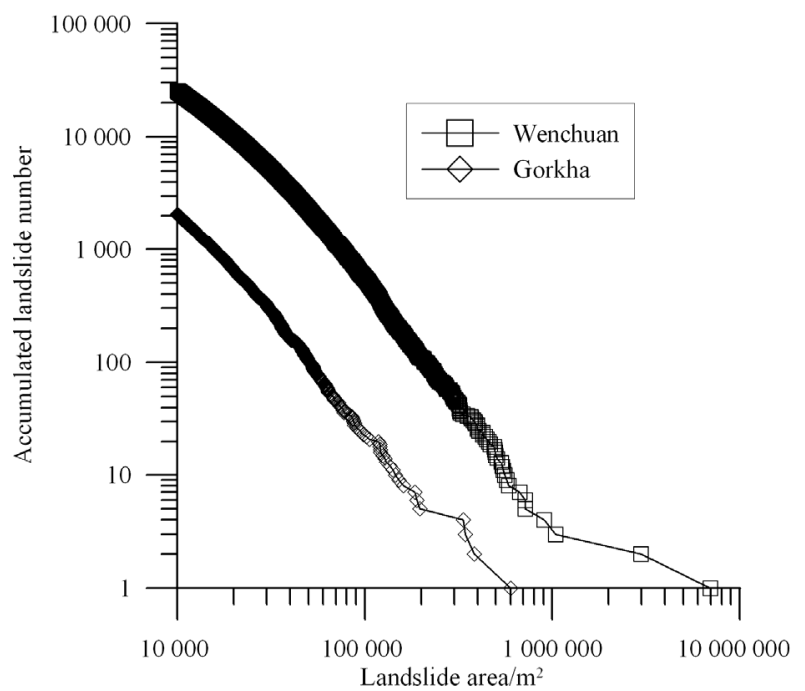

Figure 3. Relationships between coseismic landslides area $\left(\geq 10000 \mathrm{~m}^{2}\right)$ and accumulated number of the Gorkha and Wenchuan earthquakes. which is about 1.13 times that derived from Keefer's equation (Fig. 4). In other words, Keefer's formula suggests that the total landslide volumes for the two events should be similar, when they differ by more than a factor of ten! However, neither of these two volumes appears to depart greatly from the trend derived from Keefer's function (Fig. 4) due to the logarithmic scale.

Many limitations apply to power law relationships between volume and area, particularly when they are extended to individual landslides. Typically, significant volume differences can occur for landslides with comparable areas if they have different depths. Actually, many landslides triggered by the Wenchuan Earthquake are bedrock landslides with large thicknesses, whereas landslides triggered by the Gorkha Earthquake are almost all shallow landslides in regolith. For example, the Langtang Landslide $\left(28.215^{\circ} \mathrm{N}, 85.503^{\circ} \mathrm{E}\right)$, the largest triggered by the Gorkha Earthquake, covers $0.602 \times 10^{6} \mathrm{~m}^{2}$, yet the area of seven Wenchuan-event landslides is greater than this, for examples the Daguangbao Landslide $\left(31.643^{\circ} \mathrm{N}, 104.119^{\circ} \mathrm{E}\right)$, Wenjiagou $\left(31.553^{\circ} \mathrm{N}, 104.148^{\circ} \mathrm{E}\right)$ and Donghekou Landslide $\left(32.409^{\circ} \mathrm{N}, 105.109^{\circ} \mathrm{E}\right)$. The volume of the Langtang landslide is estimated as $(10.7-15.1) \times 10^{6}$ (average $12.7 \times 10^{6}$ ) $\mathrm{m}^{3}$ from the relationship $V=1.3147 \times A^{1.2085( \pm 0.0131)}$ (Xu et al., 2016), but its actual volume is only about $1.5 \times 10^{6} \mathrm{~m}^{3}$, given that its average depth is 2 to $3 \mathrm{~m}$ (Kargel et al., 2016; Collins and Jibson, 2015). Another useful comparison can be made with the Tangjiashan Landslide $\left(31.843^{\circ} \mathrm{N}, 104.432^{\circ} \mathrm{E}\right)$ triggered by the Wenchuan Earthquake, which covers an area $0.719 \times 10^{6} \mathrm{~m}^{2}$ that is comparable to the Langtang slide. The volume of $(13.2-18.8) \times 10^{6}$ (average $\left.15.7 \times 10^{6}\right) \mathrm{m}^{3}$ estimated using the power law (Xu et al., 2016) is smaller than its actual volume, about $20 \times 10^{6} \mathrm{~m}^{3}$. Other Wenchuan-event examples are the Wangjiayan $\left(31.826^{\circ} \mathrm{N}, 104.449^{\circ} \mathrm{E}\right)$ and Xinzhong $\left(31.83^{\circ} \mathrm{N}\right.$, $\left.104.459^{\circ} \mathrm{E}\right)$ landslides in Beichuan County that respectively cover $0.129 \times 10^{6}$ and $0.121 \times 10^{6} \mathrm{~m}^{2}$. They would have powerlaw volumes of about $2 \times 10^{6}$ and $1.8 \times 10^{6} \mathrm{~m}^{3}$ that are close to their actual volumes of about $2 \times 10^{6} \mathrm{~m}^{3}$, calculated by their average depths of about $15 \mathrm{~m}$. These actual volumes of the Wangjiayan and Xinzhong landslides are comparable with the largest Langtang landslide triggered by the Gorkha Earthquake. About 300 Wenchuan-event landslides covered larger areas

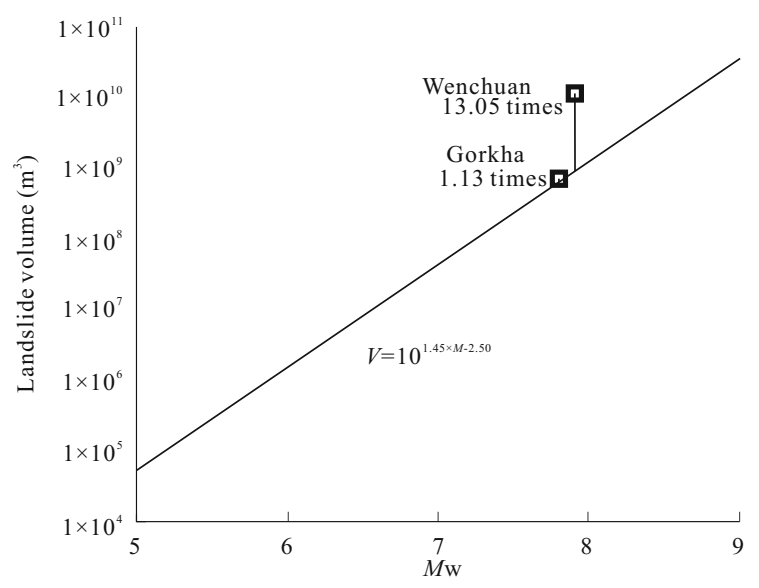

Figure 4. Empirical power law relationship between earthquake magnitude and total volume of triggered landslides. 
than the Wangjiayan and Xinzhong landslides, so several hundred Wenchuan-event landslides must be larger than the Langtang landslide. Therefore, the total volume ratio between landslides triggered by the two earthquakes should be greater than the aforementioned value by about $13.05 / 1.13=11.55$ times, normalized by earthquake magnitude. However, the uncertainty caused by various landslide depths is difficult to quantify because the actual depths and volumes remain unknown. Nevertheless, it is certain that the Gorkha-event landslides are much fewer and smaller than the Wenchuan-event landslides.

\subsection{Topography and PGA Related to the Two Earthquakes}

Coseismic landslides are generally considered to be primarily controlled by topographic, geologic, and seismic factors. To evaluate these factors, we constructed profiles along four 10 $\mathrm{km} \times 100 \mathrm{~km}$ rectangular areas G-1, G-2, W-1, and W-2, (Fig. 1) to show the topographic relief and slope steepness. The average elevation and slope angle for each $1 \mathrm{~km} \times 10 \mathrm{~km}$ segment were determined along these four rectangles. The results show that the landslide affected areas for the two earthquakes have similar topographic relief and slope steepness (Fig. 5). The topographic relief of the two profiles G-1, G-2 in the Gorkha area is mostly a little greater than that of the Wenchuan profiles, but topographic profile $\mathrm{W}-1$ shows a peak relief between distances 50 and $70 \mathrm{~km}$ (Fig. 5a). In addition, the slope steepness of profile W-1 between distances 60 and $80 \mathrm{~km}$ is greater than the values in other profiles. It is noted that this high, steep area roughly corresponds to the hanging wall of the southwest section of the seismogenic fault (YBF) of the Wenchuan Earthquake, and the greatest landslide density occurs there.

To test whether topography or PGA can explain the small number of Gorkha-event large landslides, we evaluated the correlations between the numbers of coseismic landslides and these factors. To test the influence of topography, data were divided into bins for each $10^{\circ}$ interval of slope steepness and the numbers of landslides and the landslide. Correlations between topographic relief and slope steepness for the two earth-
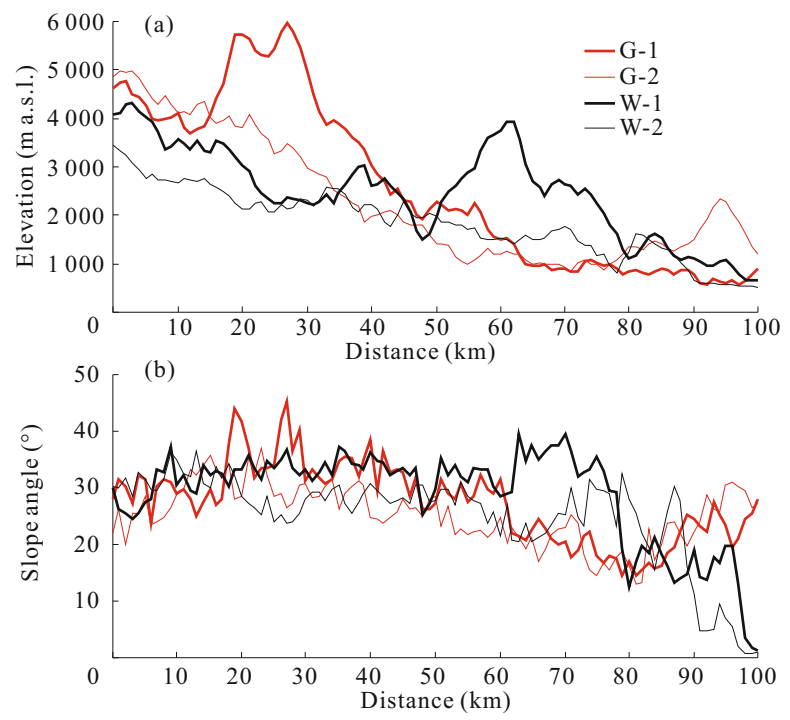

Figure 5. Curves of topographic relief (a) and slope steepness (b) along the four rectangles perpendicular to the seismogenic faults in Fig. 1. quakes are plotted against distance from the epicenter in Fig. 5 and landslide density for each slope angle bin in Fig. 6a. Areas with slope angles of $40^{\circ}-50^{\circ}$ register the largest number of landslides, and the landslide density increases with increasing slope angle, especially for the Wenchuan event. The primary difference between the curves for the two earthquakes is that the landslide numbers and densities related to the Wenchuan Earthquake are much higher than the values of the Gorkha Earthquake in every class of slope angle. Slope steepness alone cannot explain the low number of Gorkha landslides.

Similarly, we compared the correlations between PGA (US Geological Survey, 2015, 2008) and landslides for the two earthquakes, dividing the data into 0.04 interval bins for PGA. The results show that PGA had a greater influence on Wenchuan landslides than Gorkha landslides. Landslide numbers and density related to the Wenchuan Earthquake are much higher than those of the Gorkha Earthquake at the same PGA values in every PGA class (Fig. 6b). We conclude that the low capability of triggering landslides for the Gorkha Earthquake is not primarily due to strong ground shaking.

Both the areas affected by the two earthquakes are characterized by steep terrain with widespread high-angle slopes. The
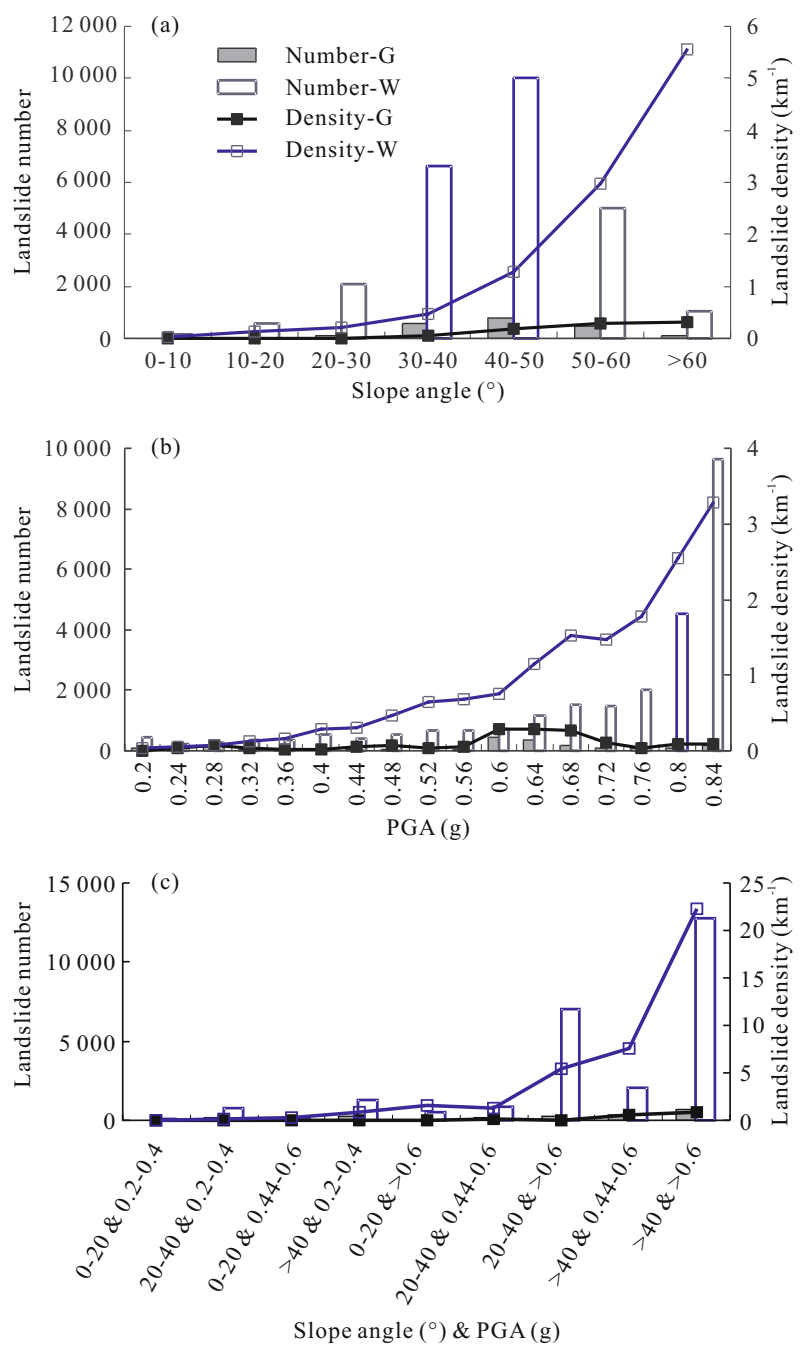

Figure 6. Relationships between coseismic landslides and slope angle (a), PGA (b), and the combination of them (c). 
distribution of PGA data related to the earthquakes shows approximate elliptical rings around the meizoseismal areas. Both the two cases show a high inconsistency between slope angle and PGA data and therefore univariate relationships between landslides, slope angle and PGA appear unlikely. In order to validate this inference, we correlated the coseismic landslides with nine combinations of slope angle and PGA (Fig. 6c). This indicates a similar result to the correlations between landslide densities, slope angle and PGA, i.e., the landslide numbers and density related to the Wenchuan Earthquake are much higher than those of the Gorkha Earthquake in any combinations of slope angle and PGA. Both slope steepness and PGA cannot explain the low number of Gorkha earthquake-triggered landslides.

\subsection{Behavior of Seismogenic Faults}

For earthquakes generated by reverse (or thrust) faults, the distribution of coseismic landslides could depend on whether surface ruptures are generated. Xu (2014) compared three indices of coseismic landslides, including landslide distribution area, landslide coverage area, and landslide number, for eight reverse-fault earthquakes, of which five had surface ruptures. The results suggest that surface-rupture earthquakes trigger fewer but larger landslides in a smaller area than buried-rupture earthquakes of comparable magnitudes. In most cases, buriedrupture earthquakes trigger relatively more landslides than those caused by surface-rupture events, as exemplified by the 1994 Northridge, USA earthquake (Harp and Jibson, 1995; Hauksson et al., 1995), 2010 Haiti (Xu et al., 2014c; Hayes et al., 2010), and the 2013 Lushan, China events (Xu X et al., 2015, 2013). The relation between the surface-rupture Wenchuan Earthquake and the buried-rupture Gorkha Earthquake is the opposite. The lack of surface ruptures for the Gorkha event cannot account for its relatively small number of associated landslides.

A significant difference between the Gorkha and Wenchuan earthquakes is that the dip of the seismogenic fault of the Wenchuan Earthquake is much steeper than that of the Gorkha Earthquake. The Gorkha Earthquake occurred at the boundary between the Indian and Eurasian plates, along a shallow fault plane (dip angle $\sim 10^{\circ}$ ), whereas the Wenchuan Earthquake occurred in the plate interior, along a steep $\left(\sim 40^{\circ}\right)$ seismogenic thrust fault. We consider that this difference of dip angle can explain the difference in the number and scale of landsides of the Wenchuan and Gorkha events. The relative magnitudes of the shear and normal components of maximum stress depend on the dip angle of the fault plane. For a reverse fault with dip angle $\alpha$ and slip displacement $L$, the maximum principal stress $(\sigma 1)$ is horizontal and perpendicular to the strike of the rupture plane (Fig. 7). Therefore, the normal stress is proportional to $L \times \tan \alpha$, and this component becomes greater as the dip angle $\alpha$ increases. The deformation of the hanging wall block is closely related to this component, and the occurrence of coseismic landslides is therefore triggered by strong ground shaking. In addition, the surface region directly above the rupture plane receives most of the earthquake energy. Because the Wenchuan Earthquake occurred along a high-angle reverse fault, the area of the surface directly overlying the fault surface was relatively small, concentrating the surface energy and resulting in many large, intense landslides. In contrast, the Gorkha Earthquake occurred along a low-angle fault, so the overlying surface area was wide, the surface energy less concentrated, and fewer smaller landslides were triggered. In short, we suggest that that these two effects determine the capability of an earthquake to trigger landslides because the dip angle of the seismogenic fault controls the manner of earthquake energy release, and thus influences the deformation of the hanging wall bedrock.

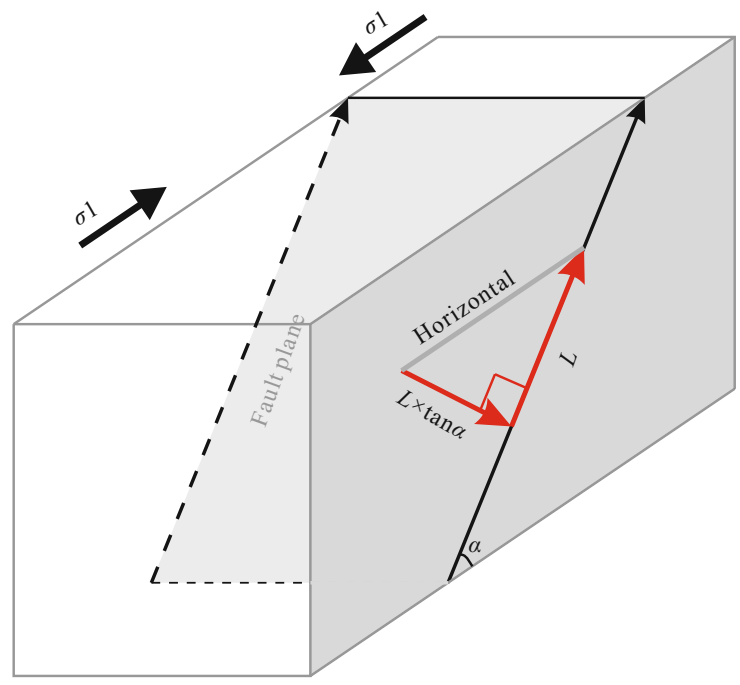

Figure 7. 3-D view of the stress components along and perpendicular to the rupture surface, and slip components on the fault surface.

\section{CONCLUSIONS}

The 2008 Wenchuan and 2015 Gorkha earthquakes have comparable magnitudes, both occurred on the margins of the Tibetan Plateau, and both are characterized by high topography and steep slopes. These similarities might suggest that the number of landslides triggered by these two events would be comparable but however, the Gorkha Earthquake triggered only 2064 large landslides $\left(\geq 10000 \mathrm{~m}^{2}\right)$, with a total area of $44.78 \times 10^{6} \mathrm{~m}^{2}$ and volume of $(444-584) \times 10^{6}$ (average $509 \times 10^{6}$ ) $\mathrm{m}^{3}$, whereas the Wenchuan Earthquake generated 25580 large landslides that cover $670.65 \times 10^{6} \mathrm{~m}^{2}$ and have a total volume of (7 128-9 479) $\times 10^{6}$ (average $8219 \times 10^{6}$ ) $\mathrm{m}^{3}$. There is only one similarity, namely that the regions of landslide generation associated with these two earthquakes have comparable areas. Our research indicates that local topography and PGA cannot explain the large difference of landsliding between the events, and the much different dip angles of their seismogenic faults is the primary reason. We suggest that high dip reverse faults cause more intense deformation of interior blocks and create larger normal stresses perpendicular to rupture surfaces, inducing joints and cracks in brittle rocks conducive to landslide generation. In contrast, fewer smaller landslides will be associated with earthquakes on reverse faults with low dip angles, for equivalent earthquake magnitude, topography, and other conditions. This study should be a valuable supplement to traditional views that coseismic landslides are mainly controlled by topography, lithology, PGA, etc.. We suggest that recognition of the important effect of fault dip angle will contribute to a better 
understanding of mechanisms giving rise to coseismic landslides, and facilitate more reliable assessments of landslide susceptibility and associated hazards.

\section{ACKNOWLEDGMENTS}

This research was supported by the National Natural Science Foundation of China (Nos. 41472202). Comments and revisions by Robert E. Criss of Washington University greatly improved the manuscript. The final publication is available at Springer via http://dx.doi.org/10.1007/s12583-016-0684-6.

Open Access This article is distributed under the terms of the Creative Commons Attribution 4.0 International License (http://creativecommons.org/licenses/by/4.0/), which permits unrestricted use, distribution, and reproduction in any medium, provided you give appropriate credit to the original authors and the source, provide a link to the Creative Commons license, and indicate if changes were made.

\section{REFERENCES CITED}

Angster, S., Fielding, E. J., Wesnousky, S., et al., 2015. Field Reconnaissance after the 25 April 2015 M 7.8 Gorkha Earthquake. Seismological Research Letters, 86(6): 1506-1513. doi:10.1785/0220150135

Bhakuni, S., Luirei, K., Kothyari, G. C., 2013. Neotectonic Fault in the Middle Part of Lesser Himalaya, Arunachal Pradesh: A Study Based on Structural and Morphotectonic Analyses. Himalayan Geology, 34(1): 57-64

British Geological Survey, Durham University, 2015. Nepal Earthquake Response 2015. [2016-10-01]. http://www.bgs.ac.uk/research/earthHazards/epom/nepalE arthquakeResponse.html

Chiaro, G., Kiyota, T., Pokhrel, R. M., et al., 2015. Reconnaissance Report on Geotechnical and Structural Damage Caused by the 2015 Gorkha Earthquake, Nepal. Soils and Foundations, 55(5): 1030-1043. doi:10.1016/j.sandf.2015.09.006

Collins, B. D., Jibson, R. W., 2015. Assessment of Existing and Potential Landslide Hazards Resulting from the April 25, 2015 Gorkha, Nepal Earthquake Sequence. US Geological Survey. doi:10.3133/ofr20151142

Galetzka, J., Melgar, D., Genrich, J. F., et al., 2015. Slip Pulse and Resonance of the Kathmandu Basin during the 2015 Gorkha Earthquake, Nepal. Science, 349(6252): 1091-1095. doi:10.1126/science.aac6383

Gorum, T., Fan, X. M., van Westen, C. J., et al., 2011. Distribution Pattern of Earthquake-Induced Landslides Triggered by the 12 May 2008 Wenchuan Earthquake. Geomorphology, 133(3-4): 152-167. doi:10.1016/j.geomorph.2010.12.030

Harp, E. L., Jibson, R. W., 1995. Inventory of Landslides Triggered by the 1994 Northridge, California Earthquake. [2016-10-01]. http://geo-nsdi.er.usgs.gov/metadata/openfile/95-213/

Hashash, Y. M. A., Tiwari, B., Moss, R. E. S., et al., 2015. Geotechnical Field Reconnaissance: Gorkha (Nepal) Earthquake of April 25, 2015 and Related Shaking Sequence. Geotechnical Extreme Event Reconnaisance
GEER Association Report No. GEER-040: 250

Hauksson, E., Jones, L. M., Hutton, K., 1995. The 1994 Northridge Earthquake Sequence in California: Seismological and Tectonic Aspects. Journal of Geophysical Research: Solid Earth (1978-2012), 100(B7): 12335-12355. doi:10.1029/95JB00865

Hayes, G. P., Briggs, R. W., Sladen, A., et al., 2010. Complex Rupture during the 12 January 2010 Haiti Earthquake. Nature Geoscience, 3(11): 800-805. doi:10.1038/ngeo977

Kargel, J. S., Leonard, G. J., Shugar, D. H., et al., 2016. Geomorphic and Geologic Controls of Geohazards Induced by Nepal's 2015 Gorkha Earthquake. Science, 351(6269): 140. doi:10.1126/science.aac 8353

Keefer, D. K., 1994. The Importance of Earthquake-Induced Landslides to Long-Term Slope Erosion and Slope-Failure Hazards in Seismically Active Regions. Geomorphology, 10(1-4): 265-284. doi:10.1016/0169-555X(94)90021-3

Kobayashi, T., Morishita, Y., Yarai, H., 2015. Detailed Crustal Deformation and Fault Rupture of the 2015 Gorkha Earthquake, Nepal, Revealed from ScanSAR-Based Interferograms of ALOS-2. Earth, Planets and Space, 67(1): 1-13. doi:10.1186/s40623-015-0359-z

Larsen, I. J., Montgomery, D. R., Korup, O., 2010. Landslide Erosion Controlled by Hillslope Material. Nature Geoscience, 3(4): 247-251. doi:10.1038/ngeo 776

Le Fort, P., 1975. Himalayas: the Collided Range. Present Knowledge of the Continental Arc. American Journal of Science, 275-A: 1-44

Lindsey, E. O., Natsuaki, R., Xu, X., et al., 2015. Line-of-Sight Displacement from ALOS-2 Interferometry: $M \mathrm{w} 7.8$ Gorkha Earthquake and Mw 7.3 Aftershock. Geophysical Research Letters, 42(16): 6655-6661. doi:10.1002/2015GL065385

Moss, R. E. S., Thompson, E. M., Kieffer, D. S., et al., 2015. Geotechnical Effects of the 2015 Magnitude 7.8 Gorkha, Nepal, Earthquake and Aftershocks. Seismological Research Letters, 86(6): 1514-1523. doi: $10.1785 / 0220150158$

Mukherjee, S., 2015. A Review on Out-of-Sequence Deformation in the Himalaya. Geological Society, London, Special Publications, 412: 412. doi:10.1144/SP412.13

Najman, Y., Appel, E., Boudagher-Fadel, M., et al., 2010. Timing of India-Asia Collision: Geological, Biostratigraphic, and Palaeomagnetic Constraints. Journal of Geophysical Research: Solid Earth (1978-2012), 115(B12). doi:10.1029/2010JB007673

Parameswaran, R. M., Natarajan, T., Rajendran, K., et al., 2015. Seismotectonics of the April-May 2015 Nepal Earthquakes: An Assessment Based on the Aftershock Patterns, Surface Effects and Deformational Characteristics. Journal of Asian Earth Sciences, 111: 161-174. doi:10.1016/j.jseaes.2015.07.030

Parker, R. N., Densmore, A. L., Rosser, N. J., et al., 2011. Mass Wasting Triggered by the 2008 Wenchuan Earthquake is Greater than Orogenic Growth. Nature Geoscience, 4(7): 449-452. doi:10.1038/ngeo1154

Searle, M. P., Law, R. D., Godin, L., et al., 2008. Defining the Himalayan Main Central Thrust in Nepal. Journal of the 
Geological Society, 165(2): 523-534. doi:10.1144/0016-76492007-081

Sun, B., Yan, P., 2015. Damage Characteristics and Seismic Capacity of Buildings During Nepal Ms 8.1 Earthquake. Earthquake Engineering and Engineering Vibration, 14(3): 571-578. doi:10.1007/s11803-015-0046-x

Upreti, B., 1999. An Overview of the Stratigraphy and Tectonics of the Nepal Himalaya. Journal of Asian Earth Sciences, 17(5): 577-606. doi:10.1016/S1367-9120(99)00047-4

US Geological Survey, 2008. Shakemap US2008ryan. [2016-10-01]. http://earthquake.usgs.gov/earthquakes/ shakemap/global/ shake/2008ryan/

US Geological Survey, 2015. Shakemap US20002926. [2016-10-01]. http://earthquake.usgs.gov/earthquakes/ shakemap/global/shake/20002926/

Wang, W. N., Wu, H. L., Nakamura, H., et al., 2003. Mass Movements Caused by Recent Tectonic Activity: The 1999 Chi-Chi Earthquake in Central Taiwan. The Island Arc, 12(4): 325-334. doi:10.1046/j.1440-1738.2003.00400.x

Wesnousky, S. G., Kumar, S., Mohindra, R., et al., 1999. Uplift and Convergence along the Himalayan Frontal Thrust of India. Tectonics, 18(6): 967-976. doi:10.1029/1999TC900026

Xu, C., 2014. Do Buried-Rupture Earthquakes Trigger Less Landslides than Surface-Rupture Earthquakes for Reverse Faults? Geomorphology, 216: 53-57. doi:10.1016/j.geomorph.2014.03.029

Xu, C., 2015. Preparation of Earthquake-Triggered Landslide Inventory Maps Using Remote Sensing and GIS Technologies: Principles and Case Studies. Geoscience Frontiers, 6(6): 825-836. doi:10.1016/j.gsf.2014.03.004

Xu, X., Wen, X., Yu, G., et al., 2009. Coseismic Reverse- and Oblique-Slip Surface Faulting Generated by the $2008 \mathrm{Mw}$ 7.9 Wenchuan Earthquake, China. Geology, 37(6): 515-518. doi:10.1130/G25462A.1

Xu, C., Xu, X., Yao, Q., et al., 2013. GIS-Based Bivariate Statistical Modelling for Earthquake-Triggered Landslides Susceptibility Mapping Related to the 2008 Wenchuan Earthquake, China. Quarterly Journal of Engineering Geology and Hydrogeology, 46(2): 221-236. doi:10.1144/qjegh2012-006

Xu, X., Wen, X., Han, Z., et al., 2013. Lushan Ms 7.0 Earthquake: A Blind Reserve-Fault Event. Chinese Science Bulletin, 58(28-29): 3437-3443. doi:10.1007/s11434-013-5999-4

Xu, C., Xu, X., Yao, X., et al., 2014a. Three (Nearly) Complete Inventories of Landslides Triggered by the May 12, 2008 Wenchuan $M \mathrm{w} 7.9$ Earthquake of China and Their Spatial Distribution Statistical Analysis. Landslides, 11(3): 441-461. doi:10.1007/s10346-013-0404-6

$\mathrm{Xu}, \mathrm{C} ., \mathrm{Xu}, \mathrm{X}$., Gorum, T., et al., 2014b. Did the 2008 Wenchuan Earthquake Lead to a Net Volume Loss? Landslide Science for a Safer Geoenvironment, Proceedings of World Landslide Forum 3, 2-6 June 2014, Beijing. 3: 191-196. doi:10.1007/978-3-319-04996-0_30

Xu, C., Shyu, J. B. H., Xu, X., 2014c. Landslides Triggered by the 12 January 2010 Port-au-Prince, Haiti, $M \mathrm{w}=7.0$ Earthquake: Visual Interpretation, Inventory Compiling, and Spatial Distribution Statistical Analysis. Natural Hazards and Earth System Sciences, 14(7): 1789-1818. doi:10.5194/nhess-14-1789-2014

Xu, C., Xu, X., Shyu, J. B. H., 2015. Database and Spatial Distribution of Landslides Triggered by the Lushan, China Mw 6.6 Earthquake of 20 April 2013. Geomorphology, 248: 77-92. doi:10.1016/j.geomorph.2015.07.002

Xu, C., Xu, X., Shen, L., et al., 2016. Optimized Volume Models of Earthquake-Triggered Landslides. Scientific Reports, 6: 29797. doi:10.1038/srep29797

Yin, Y., Wang, F., Sun, P., 2009. Landslide Hazards Triggered by the 2008 Wenchuan Earthquake, Sichuan, China. Landslides, 6(2): 139-152. doi:10.1007/s10346-009-0148-5

Yin, Y., Li, B., Wang, W., 2015. Dynamic Analysis of the Stabilized Wangjiayan Landslide in the Wenchuan Ms 8.0 Earthquake and Aftershocks. Landslides, 12(3): 537-547. doi:10.1007/s10346-014-0497-6

Zhang, Z. W., Zhou, L. Q., Cheng, W. Z., et al., 2015. Focal Mechanism Solutions of Lushan $M \mathrm{w}$ 6.6 Earthquake Sequence and Stress Field for Aftershock Zone. Earth Science-Journal of China University of Geosciences, 40(10): 1781-1793 